Article

\title{
The Pros and Cons of Polydopamine-Sensitized Titanium Oxide for the Photoreduction of $\mathrm{CO}_{2}$
}

\author{
Tongyao Wang, Ming Xia and Xueqian Kong * \\ Center for Chemistry of Novel \& High-Performance Materials, and Department of Chemistry, \\ Zhejiang University, Hangzhou 310027, China; Wangtongyao@zju.edu.cn (T.W.); Xiam@zju.edu.cn (M.X.) \\ * Correspondence: kxq@zju.edu.cn; Tel.: +86-177-6715-0513
}

Received: 17 April 2018; Accepted: 15 May 2018; Published: 17 May 2018

\begin{abstract}
Photocatalytic reduction of $\mathrm{CO}_{2}$ into fuels is a promising route to reduce greenhouse gas emission, and it demands high-performance photocatalysts that can use visible light in the solar spectrum. Due to its broadband light adsorption, polydopamine (PDA) is considered as a promising photo-sensitization material for semiconductor photocatalysts. In this work, titanium oxides have been coated with PDA through an in-situ oxidation polymerization method to pursue $\mathrm{CO}_{2}$ reduction under visible light. We have shown that the surface coated PDA with a thickness of around $1 \mathrm{~nm}$ can enhance the photocatalytic performance of anatase under visible light to reduce $\mathrm{CO}_{2}$ into $\mathrm{CO}$. Assisted with additional UV-vis adsorption and photoluminescence characterizations, we confirmed the sensitization effect of PDA on anatase. Furthermore, our study shows that thicker PDA coating might not be favorable, as PDA could decompose under both visible and UV-vis light irradiations. ${ }^{13} \mathrm{C}$ solid-state nuclear magnetic resonance showed structural differences between thin and thick PDA coatings and revealed compositional changes of PDA after light irradiation.
\end{abstract}

Keywords: photocatalysis; $\mathrm{CO}_{2}$ reduction; anatase; polydopamine; sensitization

\section{Introduction}

The large-scale consumption of fossil fuels rapidly increases atmospheric $\mathrm{CO}_{2}$ concentration that leads to the consequence of climate change. Alongside technologies to capture and sequester $\mathrm{CO}_{2}[1,2]$, photocatalytic reduction of $\mathrm{CO}_{2}$ into fuels is a promising route to turn waste into resources $[3,4]$. Ultimately, the photocatalysts could turn into artificial leaves which utilize only solar light and minimal reagents to enable a sustainable carbon cycle. To reach such ambitious goal, semiconductor materials will play a very important role owing to their desired photocatalytic activity [5,6]. In 1979, Inoue et al. [7] initially reported semiconductor including $\mathrm{TiO}_{2}, \mathrm{WO}_{3}, \mathrm{ZnO}, \mathrm{CdS}, \mathrm{GaP}$ and $\mathrm{SiC}$ as photocatalysts on reduction of $\mathrm{CO}_{2}$ into organic compounds such as methane, methanol, and formic acid. Encouraged by this pioneering work, various kinds of semiconductor photocatalysts (e.g., $\mathrm{Fe}_{2} \mathrm{O}_{3}$, $\mathrm{Cu}_{2} \mathrm{O}, \mathrm{BiVO}_{4}, \mathrm{Zn}_{2} \mathrm{GeO}_{4}$ and $\mathrm{g}_{-} \mathrm{C}_{3} \mathrm{~N}_{4}$ ) have been developed and tested, although overall their performance was far from satisfaction. The major reasons are their low chemical stability, rapid electron-hole recombination, low visible light adsorption and difficulty activating $\mathrm{CO}_{2}[8,9]$.

$\mathrm{TiO}_{2}$ is the most widely studied semiconductor photocatalyst due to its high chemical stability, low toxicity, commercial availability, and suitable energy levels of conduction and valance bands $[10,11]$. Three crystalline polymorphs of $\mathrm{TiO}_{2}$ exist in nature, anatase, rutile and brookite, which have different levels of photocatalytic activities. Limited by its wide bandgap (e.g., $3.2 \mathrm{eV}$ for anatase), however, $\mathrm{TiO}_{2}$ can only absorb UV light of the solar spectrum which is only $\sim 4 \%$ of the total solar energy. Various methods, including impurity doping, surface sensitization, oxygen vacancies, and the localized surface plasmon resonance (SPR) effect have been developed to improve the light-harvesting ability of $\mathrm{TiO}_{2}$ under visible light which accounts for $45 \%$ of energy in the solar spectrum [12-20]. Among them, 
surface sensitization is a frequently-used method that improves visible adsorption and electron/hole separation by transferring the photo-excited electron in photosensitizer to the conduction band of $\mathrm{TiO}_{2}$.

Compared to other photosensitizers such as pure organic dyes and organometallic complexes [15-20], polymer photosensitizers are more stable under photo-irradiation and in harsh environment. In this study, we focused on polydopamine (PDA), which is a polymer bioinspired by mussel adhesive proteins [21]. PDA not only is an effective surface-coating material, but also possesses unique optical and electronic properties such as broad-spectrum light adsorption and enhanced photoconductivity under the visible light irradiation [22-25]. Recently, it has been used to modify semiconductors such as $\mathrm{TiO}_{2}$ [26-28], g- $\mathrm{C}_{3} \mathrm{~N}_{4}$ [29,30], $\mathrm{Cu}_{2} \mathrm{O}$ [31], and $\beta-\mathrm{FeOOH}$ [32] and metals such as Pd [33] and $\mathrm{Ag}$ [34] to improve their photocatalytic activities by the synergetic effect of $\pi-\pi^{*}$ transition. However, up to date, almost all the studies have only reported the photodegradation of organic dyes, i.e., the photo-oxidation reaction. $\mathrm{PDA}-\mathrm{TiO}_{2}$ inorganic-organic hybrid materials have not been applied to the photoreduction of $\mathrm{CO}_{2}$. More importantly, the control of PDA sensitizer, e.g., the coating thickness and surface bonding structure is critical for the resulting photocatalytic performance. Fundamental understanding of the surface chemistry in such composite systems, however, is still rather limited.

In this work, we evaluated the photocatalytic performance of anatase-PDA (A@PDA) under UV-vis or visible light. It was found that the surface sensitizing by PDA can lead to an improved $\mathrm{CO}_{2}$ conversion into $\mathrm{CO}$. Our results suggest PDA could be a promising photosensitizer for anatase targeted for $\mathrm{CO}_{2}$ reduction applications. However, we also noticed that, although the increased thickness of PDA apparently increases the $\mathrm{CO}$ production, part of the $\mathrm{CO}$ increase could come from the photo-degradation of PDA itself as indicated by solid state NMR (SSNMR) and thermogravimetric analysis (TGA) measurements before and after reaction. SSNMR also suggests the chemical structure surface coated PDA could be quite different from the bulk as the aliphatic portions significantly increase. Our experimental work shows that, for the purpose of surface sensitization, balancing the thickness of surface layer is extremely important. It is recommended that the photocatalytic performance (especially about the organic products) should be evaluated judiciously and careful characterization of photo-stability is necessary.

\section{Results and Discussions}

\subsection{Physical and Optical Properties}

X-ray diffraction (XRD) was performed to examine the crystal structure of A@PDA. As the results shown in Figure 1a, A@PDA shows a typical pattern of anatase, while the feature of disordered PDA is not observed due to limited thickness of the surface layer. To confirm the successful PDA coating on anatase, we carried out Raman spectroscopy and transmission electron microscopy (TEM) measurements. As shown in Figure 1b, besides the four main Raman vibration modes of anatase, i.e., $141 \mathrm{~cm}^{-1}\left(E_{\mathrm{g}}\right), 395 \mathrm{~cm}^{-1}\left(B_{1 \mathrm{~g}}\right), 516 \mathrm{~cm}^{-1}\left(A_{1 \mathrm{~g}}\right)$ and $638 \mathrm{~cm}^{-1}\left(E_{\mathrm{g}}\right)[35,36]$, A@PDA also showed two broad Raman bands at around $1354 \mathrm{~cm}^{-1}$ and $1585 \mathrm{~cm}^{-1}$ which match those of pure PDA. These broad bands originate from linear stretching of $\mathrm{C}-\mathrm{C}$ bonds within the rings and in-plane stretching of the aromatic rings, similar to the D and $G$ bands of carbon nanomaterials such as graphene and graphite [37]. Moreover, TEM images (Figure 1c) of A@PDA samples show a thin surface layer of PDA whose thickness ranges from $1 \mathrm{~nm}$ to $5 \mathrm{~nm}$ depending on the amount of dopamine hydrochloride precursor added. The presence of PDA may also be confirmed by ${ }^{13} \mathrm{C}$ SSNMR, as is mentioned below.

UV-vis diffraction reflectance spectroscopy measurement (Figure 1d) shows that the light adsorption of A@PDA is in general the superposition of A-Ti and PDA. Our calculation shows that the A-Ti has a band-gap of $3.06 \mathrm{eV}$ which is in agreement with typical anatase (Figure S1).

Time-resolved photoluminescence (PL) decay (Figure 1e) is employed to study the charge carrier recombination behavior of A@PDA with different thickness of PDA. In these A@PDA samples, the fluorescence life time is increased versus anatase itself which means a longer life time of excited state that potentially benefit electron transfer for $\mathrm{CO}_{2}$ reduction. 
We also compared the specific surface area and porosity of A@PDA with anatase with $\mathrm{N}_{2}$ adsorption measurements (Figure S2). According to the classification of International Union of Pure and Applied Chemistry (IUPAC) [38], A@PDA displays a type IV isotherm, suggesting the existence of mesopore structure. The specific surface area of A@PDA is somewhat larger than anatase, and this could contribute to a higher density of active sites (Table 1).
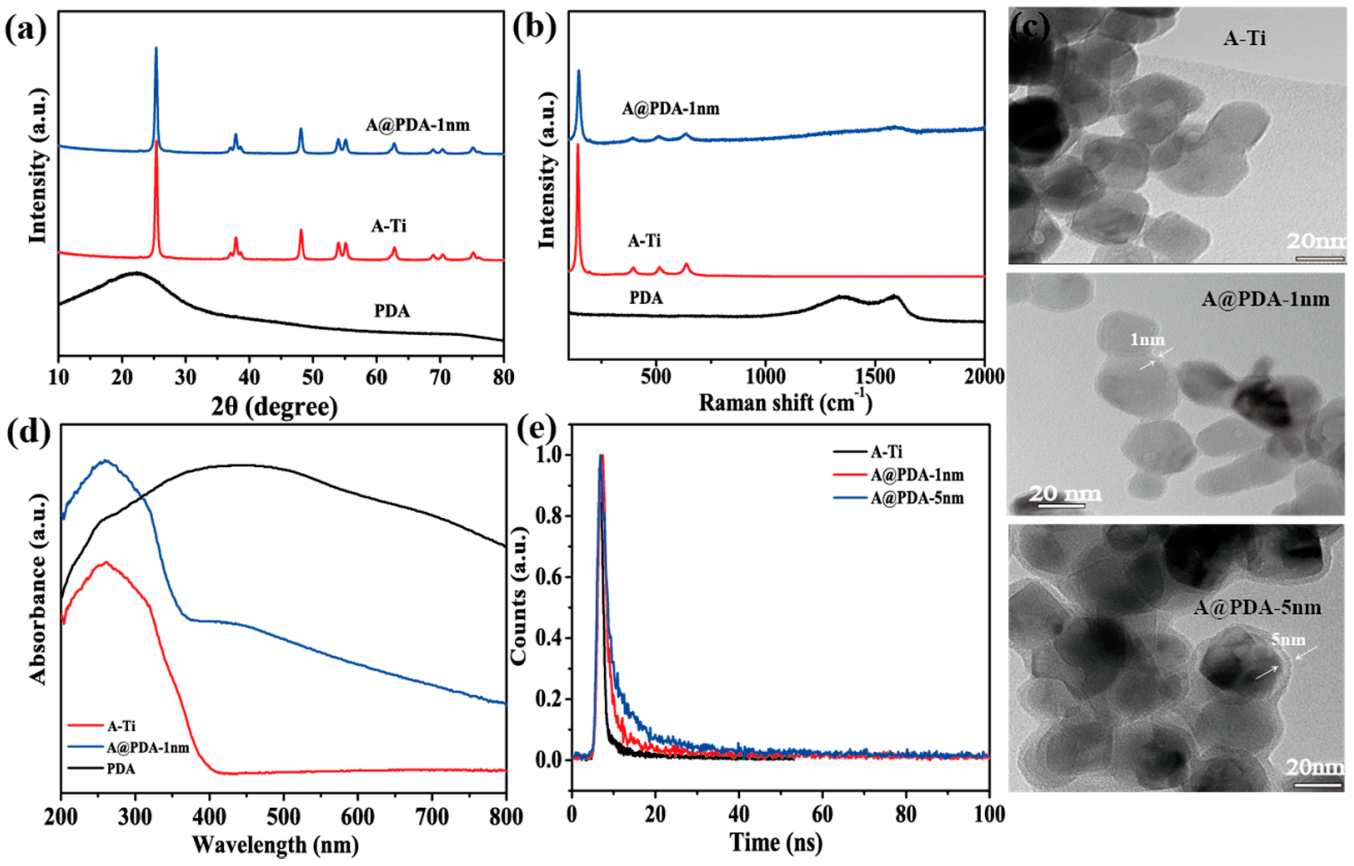

Figure 1. (a) XRD pattern and (b) Raman spectra of A@PDA-1 nm, A-Ti and PDA; (c) TEM images of A-Ti, A@PDA-1 nm, and A@PDA-5 nm; (d) UV-vis diffraction reflectance spectra of A-Ti, A@PDA-1 nm, and PDA; and (e) PL decay spectra of A-Ti, A@PDA-1 nm, and A@PDA-5 nm.

Table 1. Specific surface area, mean pore size and pore volume of the photocatalysts.

\begin{tabular}{cccc}
\hline Photocatalyst & $S_{\text {BET }}\left(\mathrm{m}^{2} / \mathrm{g}\right)$ & Mean Pore Size $(\mathrm{nm})$ & Pore Volume $\left(\mathrm{cm}^{3} / \mathrm{g}\right)$ \\
\hline A-Ti & 58.2 & 21.5 & 0.31 \\
A@PDA-1 nm & 60.1 & 23.7 & 0.36 \\
\hline
\end{tabular}

\subsection{Physical and Optical Properties}

We first evaluated the photocatalytic activity of A@PDA under visible light using the UV cut-off filter of the Xenon light. The PDA coated anatase shows an increased production of CO per gram of catalyst compared to anatase (Figure 2a). Reaction under such conditions i.e., visible light, no extra sacrificial agents, and a reduced pressure of $\mathrm{CO}_{2}$ is a viable pathway for the practical application of $\mathrm{CO}_{2}$ reduction. This again proves the sensitization effect of PDA which works through either direct electron injection [26,27], or more likely a sequential electron injection mechanism, as there is no new band in the adsorption spectrum [28].

In this work, we also tested rutile (R@PDA-1 nm) and brookite (B@PDA-1 nm) using the same PDA sensitization strategy. However, the $\mathrm{CO}_{2}$ reduction performance of R@PDA-1 nm and B@PDA-1 $\mathrm{nm}$ is worse than the pure $\mathrm{TiO}_{2}$ phases (Figures S3 and S4). It might be due to the mismatch of the excited state of PDA with the CB edge of rutile and brookite [39-41].

On the other hand, under the UV-vis range of Xenon light, the performance of anatase improves and reaches about the same level as A@PDA-1 nm (Figure 2b). By increasing the thickness of PDA, the $\mathrm{CO}$ production of A@PDA can be increased further. As the photo-generated electrons have 
a limited migration range, the photo-sensitization should take place at the shallow interface between PDA and anatase. It is not clear whether such increased CO production for the thicker PDA coating of A@PDA is due to the sensitization effect or other mechanisms such as photo-degradation of PDA itself. We therefore performed a series of control experiments and further characterized the A@PDA samples after photocatalytic reactions.
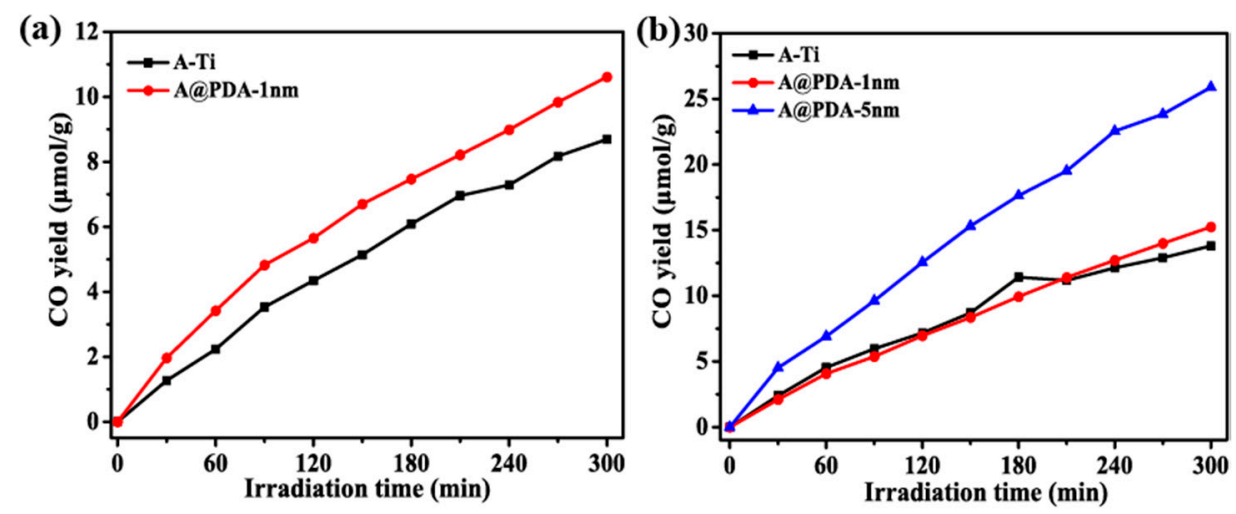

Figure 2. The comparison of CO yield for A-Ti and A@PDA-1 nm under visible light (a) and for the A-Ti, A@PDA-1 nm, and A@PDA-5 nm under UV-vis light (b) in $\mathrm{CO}_{2}$.

\subsection{Photo-Stability Evaluation}

In the literature [42,43], PDA is generally regarded as a stable compound under light irradiation and mild temperature. However, Proks et al. [44] reported that, under elevated temperatures, PDA produces a continuous evolution of $\mathrm{CO}_{2}$ and they observed that some aliphatic moieties convert into unsaturated species. Bearing this in mind, we were cautious about the extra $\mathrm{CO}$ generated by the A@PDA samples, even though it is mostly unexpected in the literature. Control experiments under UV-vis light and pure nitrogen show that both A@PDA samples can still generate CO without the reagent of $\mathrm{CO}_{2}$ (Figure 3a). The A@PDA with thicker coating generates significantly more $\mathrm{CO}$ than the thin one. As PDA is the only carbon source in the system, this inevitably proved that the surface covered PDA is not that stable under UV-vis light irradiation as people would expect. We then took a further step to study whether pure PDA itself can withstand light irradiation. As shown in Figure 3b, when the light was turned off, the PDA sample generated minimal CO suggesting it is relatively stable thermally. However, when light was on, no matter UV-vis or only visible light, extra CO was generated. This clearly indicates pure PDA also undergoes photo-degradation.

Further characterization was performed to analyze the structural evolution of A@PDA and PDA after light irradiation. Although no significant changes were detected in the TEM or XPS measurements for the PDA (Figures S5 and S6), clear changes were observed in TGA (Figure 3c) and SSNMR spectra (Figure $4 a-c)$. In the TGA experiments, the A@PDA samples after light irradiation gave less weight loss, suggesting photo-degradation eliminated part of the uncrosslinked monomers or oligomers [45]. The difference in weight-loss of the A@PDA- $1 \mathrm{~nm}$ sample is much less before and after light irradiation which in good agreement with control experiments observed in Figure 3a.

Qualitatively, ${ }^{13} \mathrm{C}$ SSNMR provides a consistent story that PDA and A@PDA-5 $\mathrm{nm}$ sample changed noticeably but not quite for the A@PDA-1 nm sample. More importantly, SSNMR can offer much more details on the changes in chemical structures [46]. In accordance to the literature [47-49], we assigned the resonances between 30 and $60 \mathrm{ppm}$ to the carbon atoms of partially saturated five-member rings and aliphatic $\mathrm{CH}_{2}-\mathrm{CH}_{2}-\mathrm{N}$ segments; the signals spanning from 110 to $150 \mathrm{ppm}$ to the aromatic species; and the peaks at between 170 and $180 \mathrm{ppm}$ to the quinones or carboxylate groups. For the PDA sample, the signals of aliphatic carbon (30-50 ppm), the protonated arene (114 ppm) and catecholic groups (145 ppm) decreased after UV-vis light irradiation (Figure 4a), whereas the spectrum of the A@PDA-1 nm sample did not vary much after irradiation despite that the signal-to-noise ratio is 
low due to the limited amount of surface coating (Figure $4 \mathrm{~b}$ ). In contrast, the signals of aliphatic carbon decreases noticeably for the A@PDA- $5 \mathrm{~nm}$ sample, indicating a thicker layer of PDA is prone to photo-decomposition (Figure 4c). These findings agree with other measurements and provide more chemical insights on how the PDA degrades under light. We reason that the self-degradation of PDA is the primary effect under such low oxygen concentrations [50]. Interestingly, ${ }^{13} \mathrm{C}$ SSNMR also suggests that the chemical compositions of PDA between sample A@PDA-1 nm and A@PDA-5 $\mathrm{nm}$ are somewhat different as the A@PDA- $1 \mathrm{~nm}$ seems to have more aliphatic portions. This could be due to either the disordered nature of the tightly bound surface structures or different polymerization mechanisms induced by the $\mathrm{TiO}_{2}$.
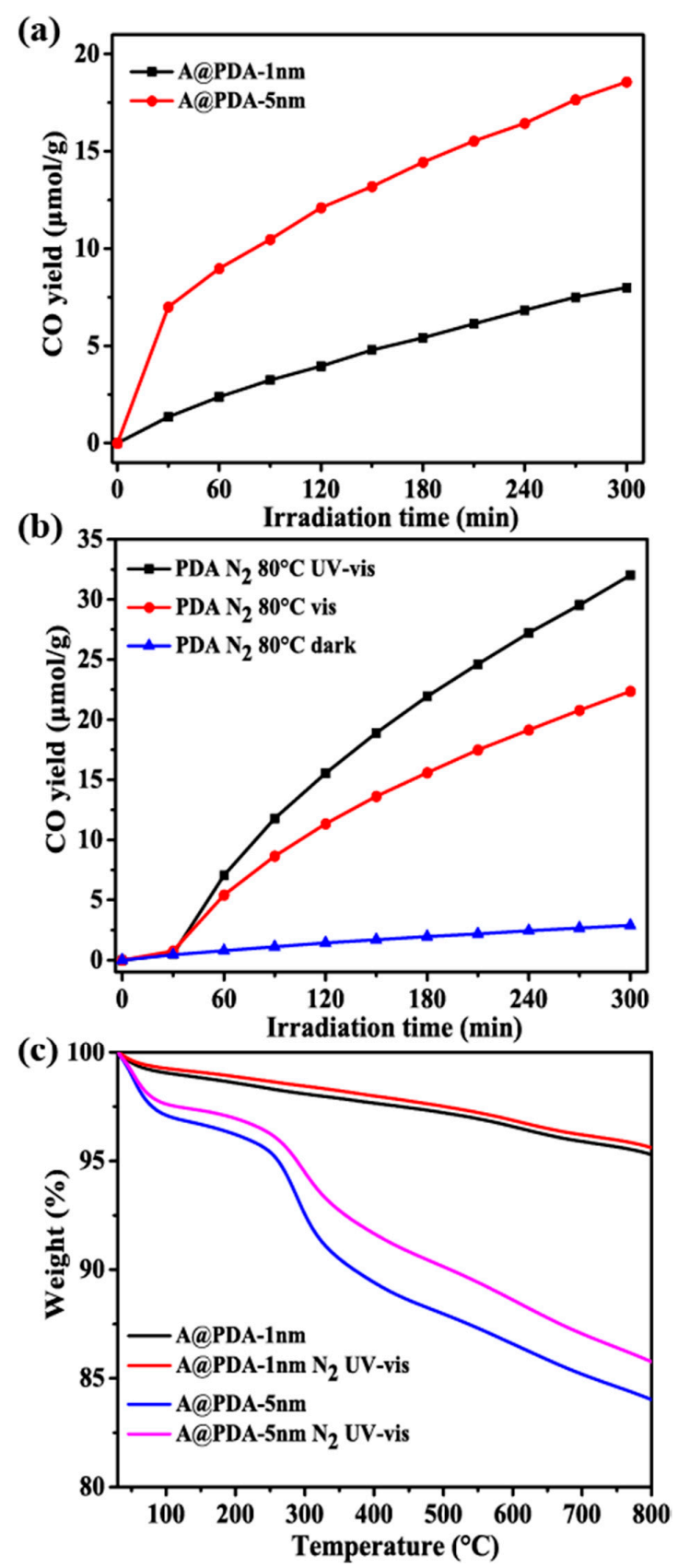

Figure 3. (a) The control experiments of A@PDA-1 nm and A@PDA-5 nm under UV-vis light in $\mathrm{N}_{2}$; (b) $\mathrm{CO}$ yields for the PDA in $\mathrm{N}_{2}$ under UV-vis light and visible light and in dark; and (c) TGA for the pristine A@PDA-1 nm and A@PDA-5 nm and them after illuminating under UV-vis light in $\mathrm{N}_{2}$ for $6 \mathrm{~h}$. 

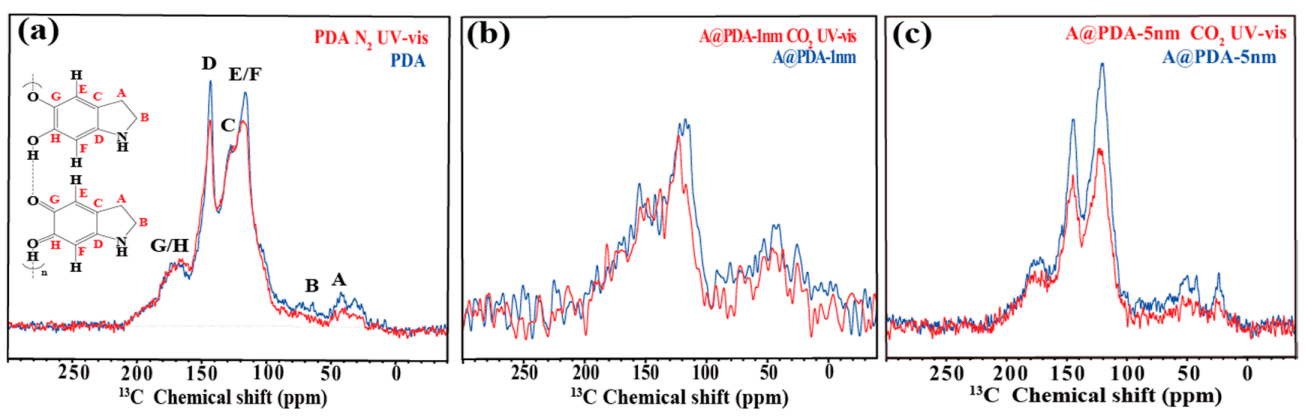

Figure 4. ${ }^{13} \mathrm{C}$ cross-polarization total suppression of spinning sidebands (CP-TOSS) spectrum of: pristine PDA and PDA after illuminating under UV-vis light in the presence of $\mathrm{N}_{2}$ for $11 \mathrm{~h}$ (a); pristine A@PDA-1 nm and A@PDA-1 nm after illuminating in $\mathrm{CO}_{2}$ for $11 \mathrm{~h}(\mathbf{b})$; and pristine A@PDA-5 nm and A@PDA-5 nm after illuminating in $\mathrm{CO}_{2}$ for $11 \mathrm{~h}$ under UV-vis light (c).

\subsection{Proposed Reaction Mechanisms}

The mechanism of $\mathrm{CO}_{2}$ photoreduction with $\mathrm{H}_{2} \mathrm{O}$ using $\mathrm{PDA}$-sensitized $\mathrm{TiO}_{2}$ under visible light is illustrated in Figure 5. According to the literature [28], the lowest unoccupied molecular orbital (LUMO) and the highest occupied molecular orbital (HOMO) of PDA are ca. -1.2 and $0.4 \mathrm{eV}$, respectively. The conduction band (CB) of anatase $\mathrm{TiO}_{2}$ is ca. $-0.5 \mathrm{eV}$ and valence band (VB) of $\mathrm{TiO}_{2}$ is at $2.56 \mathrm{eV}$. Under irradiation, the electrons on HOMO of surface-coated PDA are excited to LUMO by adsorbing a considerable amount of visible light. These photoelectrons are then transferred to the conduction band of $\mathrm{TiO}_{2}$, assisting the reduction of $\mathrm{CO}_{2}$ into $\mathrm{CO}$.

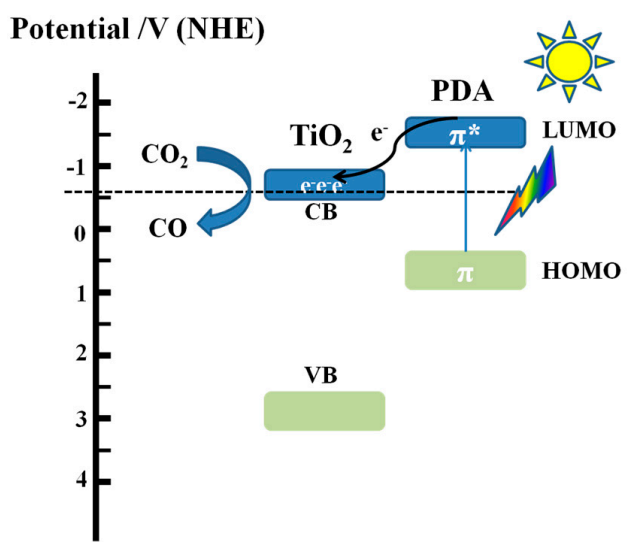

Figure 5. Illustration of the possible reaction mechanism for photoreduction of $\mathrm{CO}_{2}$ with $\mathrm{H}_{2} \mathrm{O}$ under visible light over $\mathrm{TiO}_{2} @$ PDA.

\section{Experimental Section}

\subsection{Materials and Methods}

Anatase $\mathrm{TiO}_{2}$ nano-powder $(25 \mathrm{~nm})$, named as $\mathrm{A}-\mathrm{Ti}$, and Dopamine hydrochloride were purchased from Aladdin Bio-chem Technology Co. Ltd. (Shanghai, China). Hexamethylenetetramine was purchased from Sinopharm Chemical Reagent Co. Ltd. (Shanghai, China). The anatase powder was calcinated at $450{ }^{\circ} \mathrm{C}$ for $3 \mathrm{~h}$ to improve the crystallinity and remove the organic impurity on the surface of the $\mathrm{TiO}_{2}$.

\subsubsection{Preparation of $\mathrm{TiO}_{2} @ P D A$ Composites}

The preparation of $\mathrm{TiO}_{2}-\mathrm{PDA}$ composites followed the procedures reported in the literature [26] with some modifications. First, $0.2 \mathrm{~g}$ of A-Ti and a calculated amount of dopamine hydrochloride 
were mixed with $50 \mathrm{~mL}$ of deionized water and the suspension was sonicated for $15 \mathrm{~min}$ before $0.4 \mathrm{~g}$ of hexamethylenetetramine was added. The above mixture was kept stirring for $3 \mathrm{~h}$ at $90^{\circ} \mathrm{C}$. The resulting product was obtained after centrifugation, washed thoroughly with water and dried overnight at $80{ }^{\circ} \mathrm{C}$ in an oven. The as-prepared sample is denoted as A@PDA. For the comparison, we prepared different thickness of PDA on the anatase with added dopamine hydrochloride varying from $0.02 \mathrm{~g}$ to $0.12 \mathrm{~g}$, which resulted in samples A@PDA- $1 \mathrm{~nm}$ and A@PDA- $5 \mathrm{~nm}$.

\subsubsection{Preparation of PDA}

Polydopamine was prepared according to the method reported in the literature [51]. First, $0.75 \mathrm{~mL}$ ammonia aqueous solution $\left(\mathrm{NH}_{4} \mathrm{OH}, 28-30 \%\right)$ was added to the mixture of ethanol $(40 \mathrm{~mL})$ and deionized water $(90 \mathrm{~mL})$ under mild stirring at room temperature for $30 \mathrm{~min}$. Second, $0.5 \mathrm{~g}$ of dopamine hydrochloride was dissolved in deionized water $(10 \mathrm{~mL})$ and then added to the mixture above under mild stirring. The mixture was kept for $30 \mathrm{~h}$ at room temperature. The resulting product was collected, washed thoroughly with water and dried overnight at $80^{\circ} \mathrm{C}$ in an oven.

\subsection{Characterizations}

X-ray diffraction (XRD) patterns of the materials were collected on an Ultima IV X-ray diffractometer (Rigaku, Tokyo, Japan) with $\mathrm{Cu} \mathrm{K} \alpha$ irradiation in the $2 \theta$ range of $10-80^{\circ}$. Raman spectra were recorded on a Labor Raman HR-800 (JobinYvon, Longjumeau, France) with an $\mathrm{Ar}^{+}$laser excitation at $514 \mathrm{~nm}$. Transmission electron microscopy (TEM) (Hitachi HT7700, Tokyo, Japan) was used to obtain the morphologies of the materials. The UV-vis diffuse reflectance spectra of the samples over the range of 200-800 nm were obtained on a Shimadzu UV-2600 UV-vis spectrophotometer with an integration sphere diffuse reflectance attachment using $\mathrm{BaSO}_{4}$ as the reference. The time-resolved photoluminescence (PL) decay measurements for the solid samples were investigated on an Edinburgh FLSP920 spectrometer, the laser device of $340 \mathrm{~nm}$ was used to get the laser beam. The surface area and porosity were analyzed by nitrogen adsorption at $77 \mathrm{~K}$ on a gas adsorption apparatus (MicrotracBEL, BELSORP-max, Osaka, Japan). Thermogravimetric analysis (TGA) was performed in $\mathrm{N}_{2}$ using a SDT Q600 V20.9 Build 20 thermogravimetric analyzer (TA Instruments, New Castle, DE, USA) from $30{ }^{\circ} \mathrm{C}$ to $800{ }^{\circ} \mathrm{C}$ with a heating rate of $10^{\circ} \mathrm{C} \mathrm{min}^{-1}$. X-ray photoelectron spectroscopy (XPS) measurements were conducted on an Esclab MARK II spectrometer (VG Scientific, West Sussex, UK). The solid-state NMR (SSNMR) experiments were performed on a Bruker 14.1T magnet in 3.2-mm $\mathrm{ZrO}_{2}$ rotors. The ${ }^{13} \mathrm{C}$ Cross-Polarization Total Suppression of Spinning Sidebands (CP-TOSS) NMR spectra were measured at a spinning rate of $10 \mathrm{kHz}$. The ${ }^{13} \mathrm{C}$ chemical shifts were referenced to adamantane at $38.4 \mathrm{ppm}$. A CP contact time was set to $2 \mathrm{~ms}$. A total of 10,240 scans were accumulated for each spectrum. All experiments were conducted at room temperature.

\subsection{Photocatalytic Reactions}

$\mathrm{CO}_{2}$ photocatalytic reduction in the presence of water was performed with a homemade stainless-steel photocatalytic reactor. The total volume of the reactor was about $415 \mathrm{~mL}$. A $300 \mathrm{~W}$ Xe arc lamp (PL-X300D, Beijing Precise Technology Co. Ltd., Beijing, China) equipped with a UV cut-off filter $(\lambda \geq 400 \mathrm{~nm})$ was used as the UV-vis light source and visible light source and it was positioned $\sim 7.5 \mathrm{~cm}$ above the quartz boat. The UV-vis light intensity measured using a radiometer was ca. $220 \mathrm{~mW} / \mathrm{cm}^{2}$ and the visible light intensity was ca. $150 \mathrm{~mW} / \mathrm{cm}^{2}$. In a typical experiment, $30 \mathrm{mg}$ solid photocatalyst was placed in a quartz boat inside the closed quartz tube. A culture dish containing $4 \mathrm{~mL}$ water was placed at the side of the quartz tube, which supplies water vapor to the system. Before light irradiation, the reactor was sealed and was subjected to vacuum degassing at room temperature and then backfilled the mixture of $\mathrm{N}_{2}$ and $\mathrm{CO}_{2}(v / v 90 / 10)$ until the pressure rose slightly above $1 \mathrm{bar}$. The temperature of the reactor was maintained at $80^{\circ} \mathrm{C}$. The gas products from the reactor were analyzed at a 30-min interval using an online gas chromatography (Fuli GC-9790, Wenling, China) equipped with a flame ionized detector (FID) and methanizer. 


\section{Conclusions}

In summary, core-shell structured $\mathrm{TiO}_{2} @ \mathrm{PDA}$ samples were prepared and they exhibited improved $\mathrm{CO}$ yield under visible light, confirming the sensitization effect of PDA. On the other hand, even though thicker PDA coating may lead to higher $\mathrm{CO}$ yield, part of the CO product could come from the photodegradation of PDA itself, as indicated by SSNMR and TGA. To achieve better $\mathrm{CO}_{2}$ reduction performance, further investigations on polymer sensitized semiconductors are needed. Meanwhile, the photo-stability of the organic components has to be carefully evaluated and optimized.

Supplementary Materials: The following are available online at http:/ /www.mdpi.com/2073-4344/8/5/215/s1, Figure S1: The plot of $(\alpha \mathrm{h} v)^{1 / 2}$ versus $\mathrm{h} v$ for the bandgap calculation of A-Ti, Figure S2: (a) Nitrogen adsorption and desorption isotherms; and (b) pore size distribution curves of A-Ti and A@PDA-1 nm, Figure S3: CO yield comparison of R-Ti and R@PDA-1 nm under Visible light (a) and UV-vis light (b) for the photoreduction of $\mathrm{CO}_{2}$, Figure S4: CO yield comparison of B-Ti and B@PDA-1 nm under Visible light (a) and UV-vis light (b) for the photoreduction of $\mathrm{CO}_{2}$, Figure S5: TEM images of : (a) pristine PDA; and (b) PDA after illuminating under UV-vis light in $\mathrm{N}_{2}$ for $6 \mathrm{~h}$, Figure S6: XPS spectra of PDA and PDA after illuminating under UV-vis light in $\mathrm{N}_{2}$ for $6 \mathrm{~h}$ : (a) C1s; (b) N1s; and (c) O1s.

Author Contributions: X.K. and T.W. conceived and designed the experiments; T.W. performed the experiments; T.W. analyzed the data; M.X. contributed reagents/materials/analysis tools; and T.W. and X.K. wrote the paper.

Acknowledgments: This work was financially supported by National Natural Science Foundation of China (No. 21573197) and State Key Laboratory of Chemical Engineering No. SKL-ChE-16D03. The authors are grateful to the School of Materials Science and Engineering of Zhejiang University for providing the characterizations of time-resolved PL decay in this paper.

Conflicts of Interest: The authors declare no conflict of interest.

\section{References}

1. D'Alessandro, D.M.; Smit, B.; Long, J.R. Carbon Dioxide Capture: Prospects for New Materials. Angew. Chem. Int. Ed. 2010, 49, 6058-6082. [CrossRef] [PubMed]

2. Yaumi, A.L.; Abu Bakar, M.Z.; Hameed, B.H. Recent advances in functionalized composite solid materials for carbon dioxide capture. Energy 2017, 124, 461-480. [CrossRef]

3. Lewis, N.S.; Nocera, D.G. Powering the planet: Chemical challenges in solar energy utilization. Proc. Natl. Acad. Sci. USA 2006, 103, 15729-15735. [CrossRef] [PubMed]

4. Habisreutinger, S.N.; Schmidt-Mende, L.; Stolarczyk, J.K. Photocatalytic Reduction of $\mathrm{CO}_{2}$ on $\mathrm{TiO}_{2}$ and Other Semiconductors. Angew. Chem. Int. Ed. 2013, 52, 7372-7408. [CrossRef] [PubMed]

5. Hoffmann, M.R.; Martin, S.T.; Choi, W.Y.; Bahnemann, D.W. Environmental applications of semiconductor photocatalysis. Chem. Rev. 1995, 95, 69-96. [CrossRef]

6. Zhou, Y.; Tu, W.G.; Zou, Z.G. New Materials for $\mathrm{CO}_{2}$ Photoreduction. In Photocatalysis: Fundamentals and Perspectives; Schneider, J., Bahnemann, D., Ye, J.H., Puma, G.L., Dionysiou, D.D., Eds.; The Royal Society of Chemistry: Cambridge, UK, 2016; pp. 318-322. ISBN 978-1-78262-041-9.

7. Inoue, T.; Fujishima, A.; Konishi, S.; Honda, K. Photoelectrocatalytic reduction of carbon dioxide in aqueous suspensions of semiconductor powders. Nature 1979, 277, 637-638. [CrossRef]

8. Li, X.; Wen, J.Q.; Low, J.X.; Fang, Y.P.; Yu, J.G. Design and fabrication of semiconductor photocatalyst for photocatalytic reduction of $\mathrm{CO}_{2}$ to solar fuel. Sci. China Mater. 2014, 57, 70-100. [CrossRef]

9. Chang, X.X.; Wang, T.; Gong, J.L. $\mathrm{CO}_{2}$ photo-reduction: Insights into $\mathrm{CO}_{2}$ activation and reaction on surfaces of photocatalysts. Energy Environ. Sci. 2016, 9, 2177-2196. [CrossRef]

10. Carp, O.; Huisman, C.L.; Reller, A. Photoinduced reactivity of titanium dioxide. Prog. Solid State Chem. 2004, 32, 33-177. [CrossRef]

11. Ma, Y.; Wang, X.L.; Jia, Y.S.; Chen, X.B.; Han, H.X.; Li, C. Titanium Dioxide-Based Nanomaterials for Photocatalytic Fuel Generations. Chem. Rev. 2014, 114, 9987-10043. [CrossRef] [PubMed]

12. Liu, G.H.; Hoivik, N.; Wang, K.Y.; Jakobsen, H. Engineering $\mathrm{TiO}_{2}$ nanomaterials for $\mathrm{CO}_{2}$ conversion/solar fuels. Sol. Energy Mater. Sol. Cells 2012, 105, 53-68. [CrossRef]

13. Das, S.; Daud, W. Photocatalytic $\mathrm{CO}_{2}$ transformation into fuel: A review on advances in photocatalyst and photoreactor. Renew. Sustain. Energy Rev. 2014, 39, 765-805. [CrossRef] 
14. Zhao, H.L.; Pan, F.P.; Li, Y. A review on the effects of $\mathrm{TiO}_{2}$ surface point defects on $\mathrm{CO}_{2}$ photoreduction with $\mathrm{H}_{2}$ O. J. Materiomics 2017, 3, 17-32. [CrossRef]

15. Ozcan, O.; Yukruk, F.; Akkaya, E.U.; Uner, D. Dye sensitized artificial photosynthesis in the gas phase over thin and thick $\mathrm{TiO}_{2}$ films under UV and visible light irradiation. Appl. Catal. B Environ. 2007, 71, 291-297. [CrossRef]

16. Nguyen, T.V.; Wu, J.C.S.; Chiou, C.H. Photoreduction of $\mathrm{CO}_{2}$ over Ruthenium dye-sensitized $\mathrm{TiO}_{2}$-based catalysts under concentrated natural sunlight. Catal. Commun. 2008, 9, 2073-2076. [CrossRef]

17. Qin, G.H.; Zhang, Y.; Ke, X.B.; Tong, X.L.; Sun, Z.; Liang, M.; Xue, S. Photocatalytic reduction of carbon dioxide to formic acid, formaldehyde, and methanol using dye-sensitized $\mathrm{TiO}_{2}$ film. Appl. Catal. B Environ. 2013, 129, 599-605. [CrossRef]

18. Won, D.I.; Lee, J.S.; Ji, J.M.; Jung, W.J.; Son, H.J.; Pac, C.; Kang, S.O. Highly Robust Hybrid Photocatalyst for Carbon Dioxide Reduction: Tuning and Optimization of Catalytic Activities of Dye $/ \mathrm{TiO}_{2} / \operatorname{Re}(\mathrm{I})$ Organic-Inorganic Ternary Systems. J. Am. Chem. Soc. 2015, 137, 13679-13690. [CrossRef] [PubMed]

19. Do, J.Y.; Tamilavan, V.; Agneeswari, R.; Hyun, M.H.; Kang, M. Synthesis and optical properties of TDQD and effective $\mathrm{CO}_{2}$ reduction using a TDQD-photosensitized $\mathrm{TiO}_{2}$ film. J. Photochem. Photobiol. A Chem. 2016, 330, 30-36. [CrossRef]

20. Huang, H.W.; Lin, J.J.; Zhu, G.B.; Weng, Y.X.; Wang, X.X.; Fu, X.Z.; Long, J.L. A Long-Lived Mononuclear Cyclopentadienyl Ruthenium Complex Grafted onto Anatase $\mathrm{TiO}_{2}$ for Efficient $\mathrm{CO}_{2} \mathrm{Photoreduction}$ Angew. Chem. Int. Ed. 2016, 55, 8314-8318. [CrossRef] [PubMed]

21. Lee, H.; Dellatore, S.M.; Miller, W.M.; Messersmith, P.B. Mussel-inspired surface chemistry for multifunctional coatings. Science 2007, 318, 426-430. [CrossRef] [PubMed]

22. Pezzella, A.; Iadonisi, A.; Valerio, S.; Panzella, L.; Napolitano, A.; Adinolfi, M.; d'Ischia, M. Disentangling Eumelanin "Black Chromophore": Visible Absorption Changes As Signatures of Oxidation State- and Aggregation-Dependent Dynamic Interactions in a Model Water-Soluble 5,6-Dihydroxyindole Polymer. J. Am. Chem. Soc. 2009, 131, 15270-15275. [CrossRef] [PubMed]

23. Liu, Y.L.; Ai, K.L.; Lu, L.H. Polydopamine and Its Derivative Materials: Synthesis and Promising Applications in Energy, Environmental, and Biomedical Fields. Chem. Rev. 2014, 114, 5057-5115. [CrossRef] [PubMed]

24. D'Ischia, M.; Napolitano, A.; Ball, V.; Chen, C.T.; Buehler, M.J. Polydopamine and Eumelanin: From Structure-Property Relationships to a Unified Tailoring Strategy. Acc. Chem. Res. 2014, 47, 3541-3550. [CrossRef] [PubMed]

25. Son, E.J.; Kim, J.H.; Kim, K.; Park, C.B. Quinone and its derivatives for energy harvesting and storage materials. J. Mater. Chem. A 2016, 4, 11179-11202. [CrossRef]

26. Mao, W.X.; Lin, X.J.; Zhang, W.; Chi, Z.X.; Lyu, R.W.; Cao, A.M.; Wan, L.J. Core-shell structured $\mathrm{TiO}_{2} @$ polydopamine for highly active visible-light photocatalysis. Chem. Commun. 2016, 52, 7122-7125. [CrossRef] [PubMed]

27. Zhou, X.S.; Jin, B.; Luo, J.; Xu, X.Y.; Zhang, L.L.; Li, J.J.; Guan, H.J. Dramatic visible light photocatalytic degradation due to the synergetic effects of $\mathrm{TiO}_{2}$ and PDA nanospheres. RSC Adv. 2016, 6, 64446-64449. [CrossRef]

28. Kim, S.; Moon, G.H.; Kim, G.; Kang, U.; Park, H.; Choi, W. $\mathrm{TiO}_{2}$ complexed with dopamine-derived polymers and the visible light photocatalytic activities for water pollutants. J. Catal. 2017, 346, 92-100. [CrossRef]

29. He, F.; Chen, G.; Yu, Y.G.; Zhou, Y.S.; Zheng, Y.; Hao, S. The synthesis of condensed C-PDA-g-C $3 \mathrm{~N}_{4}$ composites with superior photocatalytic performance. Chem. Commun. 2015, 51, 6824-6827. [CrossRef] [PubMed]

30. Yu, Z.X.; Li, F.; Yang, Q.B.; Shi, H.; Chen, Q.; Xu, M. Nature-Mimic Method To Fabricate Polydopamine/Graphitic Carbon Nitride for Enhancing Photocatalytic Degradation Performance. ACS Sustain. Chem. Eng. 2017, 5, 7840-7850. [CrossRef]

31. Zhou, X.S.; Jin, B.; Luo, J.; Gu, X.X.; Zhang, S.Q. Photoreduction preparation of $\mathrm{Cu}_{2} \mathrm{O} @$ polydopamine nanospheres with enhanced photocatalytic activity under visible light irradiation. J. Solid State Chem. 2017, 254, 55-61. [CrossRef]

32. Zhang, C.; Yang, H.C.; Wan, L.S.; Liang, H.Q.; Li, H.Y.; Xu, Z.K. Polydopamine-Coated Porous Substrates as a Platform for Mineralized beta-FeOOH Nanorods with Photocatalysis under Sunlight. ACS Appl. Mater. Interfaces 2015, 7, 11567-11574. [CrossRef] [PubMed]

33. Xie, A.M.; Zhang, K.; Wu, F.; Wang, N.N.; Wang, Y.; Wang, M.Y. Polydopamine nanofilms as visible light-harvesting interfaces for palladium nanocrystal catalyzed coupling reactions. Catal. Sci. Technol. 2016, 6, 1764-1771. [CrossRef] 
34. Feng, J.J.; Zhang, P.P.; Wang, A.J.; Liao, Q.C.; Xi, J.L.; Chen, J.R. One-step synthesis of monodisperse polydopamine-coated silver core-shell nanostructures for enhanced photocatalysis. New J. Chem. 2012, 36, 148-154. [CrossRef]

35. Ohsaka, T. Temperature dependence of the Raman spectrum in anatase $\mathrm{TiO}_{2}$. J. Phys. Soc. Jpn. 1980, 48, 1661-1668. [CrossRef]

36. Choi, H.C.; Jung, Y.M.; Kim, S.B. Size effects in the Raman spectra of $\mathrm{TiO}_{2}$ nanoparticles. Vib. Spectrosc. 2005, 37, 33-38. [CrossRef]

37. Ye, W.C.; Wang, D.A.; Zhang, H.; Zhou, F.; Liu, W.M. Electrochemical growth of flowerlike gold nanoparticles on polydopamine modified ITO glass for SERS application. Electrochim. Acta 2010, 55, 2004-2009. [CrossRef]

38. Thommes, M.; Kaneko, K.; Neimark, A.V.; Olivier, J.P.; Rodriguez-Reinoso, F.; Rouquerol, J.; Sing, K.S.W. Physisorption of gases, with special reference to the evaluation of surface area and pore size distribution (IUPAC Technical Report). Pure Appl. Chem. 2015, 87, 1051-1069. [CrossRef]

39. Magne, C.; Dufour, F.; Labat, F.; Lancel, G.; Durupthy, O.; Cassaignon, S.; Pauporte, T. Effects of TiO 2 nanoparticle polymorphism on dye-sensitized solar cell photovoltaic properties. J. Photochem. Photobiol. A Chem. 2012, 232, 22-31. [CrossRef]

40. Akimov, A.V.; Neukirch, A.J.; Prezhdo, O.V. Theoretical Insights into Photoinduced Charge Transfer and Catalysis at Oxide Interfaces. Chem. Rev. 2013, 113, 4496-4565. [CrossRef] [PubMed]

41. Lin, H.; Fratesi, G.; Selcuk, S.; Brivio, G.P.; Selloni, A. Effects of Thermal Fluctuations on the Structure, Level Alignment, and Absorption Spectrum of Dye-Sensitized $\mathrm{TiO}_{2}$ : A Comparative Study of Catechol and Isonicotinic Acid on the Anatase (101) and Rutile (110) Surfaces. J. Phys. Chem. C 2016, 120, 3899-3905. [CrossRef]

42. Phua, S.L.; Yang, L.P.; Toh, C.L.; Ding, G.Q.; Lau, S.K.; Dasari, A.; Lu, X.H. Simultaneous Enhancements of UV Resistance and Mechanical Properties of Polypropylene by Incorporation of Dopamine-Modified Clay. ACS Appl. Mater. Interfaces 2013, 5, 1302-1309. [CrossRef] [PubMed]

43. Yang, X.; Duan, L.; Cheng, X.J.; Ran, X.Q. Effect of polydopamine coating on improving photostability of poly(1,3,4-oxadiazole)s fiber. J. Polym. Res. 2016, 23. [CrossRef]

44. Proks, V.; Brus, J.; Pop-Georgievski, O.; Vecernikova, E.; Wisniewski, W.; Kotek, J.; Urbanova, M.; Rypacek, F. Thermal-Induced Transformation of Polydopamine Structures: An Efficient Route for the Stabilization of the Polydopamine Surfaces. Macromol. Chem. Phys. 2013, 214, 499-507. [CrossRef]

45. Wang, Z.H.; Tang, F.; Fan, H.L.; Wang, L.; Jin, Z.X. Polydopamine Generates Hydroxyl Free Radicals under Ultraviolet-Light Illumination. Langmuir 2017, 33, 5938-5946. [CrossRef] [PubMed]

46. Marchetti, A.; Chen, J.E.; Pang, Z.F.; Li, S.H.; Ling, D.S.; Deng, F.; Kong, X.Q. Understanding Surface and Interfacial Chemistry in Functional Nanomaterials via Solid-State NMR. Adv. Mater. 2017, 29. [CrossRef] [PubMed]

47. Adhyaru, B.B.; Akhmedov, N.G.; Katritzky, A.R.; Bowers, C.R. Solid-state cross-polarization magic angle spinning ${ }^{13} \mathrm{C}$ and ${ }^{15} \mathrm{~N}$ NMR characterization of Sepia melanin, Sepia melanin free acid and Human hair melanin in comparison with several model compounds. Magn. Reson. Chem. 2003, 41, 466-474. [CrossRef]

48. Dreyer, D.R.; Miller, D.J.; Freeman, B.D.; Paul, D.R.; Bielawski, C.W. Elucidating the Structure of Poly(dopamine). Langmuir 2012, 28, 6428-6435. [CrossRef] [PubMed]

49. Liebscher, J.; Mrowczynski, R.; Scheidt, H.A.; Filip, C.; Hadade, N.D.; Turcu, R.; Bende, A.; Beck, S. Structure of Polydopamine: A Never-Ending Story? Langmuir 2013, 29, 10539-10548. [CrossRef] [PubMed]

50. Gaya, U.I.; Abdullah, A.H. Heterogeneous photocatalytic degradation of organic contaminants over titanium dioxide: A review of fundamentals, progress and problems. J. Photochem. Photobiol. C: Photochem. Rev. 2008, 9,1-12. [CrossRef]

51. Ai, K.L.; Liu, Y.L.; Ruan, C.P.; Lu, L.H.; Lu, G.Q. Sp2 C-Dominant N-Doped Carbon Sub-micrometer Spheres with a Tunable Size: A Versatile Platform for Highly Efficient Oxygen-Reduction Catalysts. Adv. Mater. 2013, 25, 998-1003. [CrossRef] [PubMed]

(C) 2018 by the authors. Licensee MDPI, Basel, Switzerland. This article is an open access article distributed under the terms and conditions of the Creative Commons Attribution (CC BY) license (http:/ / creativecommons.org/licenses/by/4.0/). 